\title{
Marguerite de Cambis, Epistre consolatoire de messire Jean Boccace envoyée au Seigneur Pino de Rossi
}

\section{Dario Cecchetti}

\section{(2) OpenEdition}

1 Journals

\section{Edizione digitale}

URL: https://journals.openedition.org/studifrancesi/40467

DOI: 10.4000/studifrancesi.40467

ISSN: 2421-5856

\section{Editore}

Rosenberg \& Sellier

\section{Edizione cartacea}

Data di pubblicazione: 1 juillet 2004

Paginazione: 172

ISSN: 0039-2944

\section{Notizia bibliografica digitale}

Dario Cecchetti, «Marguerite de Cambis, Epistre consolatoire de messire Jean Boccace envoyée au Seigneur Pino de Rossi», Studi Francesi [Online], 142 (XLVIII | I) | 2004, online dal 30 novembre 2015, consultato il 09 septembre 2021. URL: http://journals.openedition.org/studifrancesi/40467 ; DOI: https://doi.org/10.4000/studifrancesi.40467

\section{Questo documento è stato generato automaticamente il 9 septembre 2021.}

\section{(c) (1)}

Studi Francesi è distribuita con Licenza Creative Commons Attribuzione - Non commerciale - Non opere derivate 4.0 Internazionale. 


\title{
Marguerite de Cambis, Epistre consolatoire de messire Jean Boccace envoyée au Seigneur Pino de Rossi
}

\author{
Dario Cecchetti
}

\section{NOTIZIA}

MARGUERITE DE CAMBIS, Epistre consolatoire de messire Jean Boccace envoyée au Seigneur Pino de Rossi, texte établi, commenté et annoté par Colette H. winN, Paris, Champion, 2003, pp.

LXX-90.

1 Colette Winn offre l'edizione critica della traduzione ad opera di Marguerite de Cambis, pubblicata a Lione da Guillaume Rouillé nel 1556, della lettera di Boccaccio a Pino de' Rossi del 1361-1362, che ebbe, come esempio di consolatoria, grande diffusione manoscritta e usufruì, a partire dal 1487, di numerose edizioni a stampa (15 ne repertoria Colette Winn, fino al 1545) ove compare quasi sempre insieme al Laberinto d'Amore. Marguerite apparteneva a quella famiglia fiorentina dei Cambi che in seguito alla congiura dei Pazzi aveva dovuto andare in esilio nel sud della Francia ove, verso la metà del Cinquecento, occupava una posizione di spicco. In possesso di una padronanza perfetta sia della lingua francese sia di quella italiana, Marguerite, che aveva già tradotto, sempre per i tipi di Guillaume Rouillé, una lettera - anch'essa trattatello morale - di Trissino (Epistre du Seigneur Jean Georges Tryssin, de la vie que doit tenir une Dame veuve), rivolgendosi a un autore come Boccaccio, la cui opera è nel Cinquecento quasi integralmente tradotta in francese, dichiara di avere accesso ai libri italiani provenienti dalla «tant fameuse cité de Florence, vraye Academie de bien et proprement parler» e di volere «faire entendre en [sa] langue Françoise aux damoiselles [ses] amyes et bonnes voisines, non accoustumées en la Tuscane, aucuns beaux et bons livres des gens doctes d'Italie» (p. 2). La scelta di tradurre l'epistola, oltre al fatto che si tratta di uno dei pochi testi boccacciani non ancora tradotti in francese, è dovuta in parte a motivazioni sociologiche: in un'epoca in cui la traduzione (ad 
eccezione di quella di scritti religiosi e di pietà) è considerata compito maschile, la versione della consolatoria appare - e Marguerite lo sottolinea - esercizio virtuoso e onesto. Tuttavia, al di là di queste motivazioni, Marguerite - afferma Colette Winn «vuole valorizzare il ruolo esercitato dalla traduttrice nell'avvenire della cultura francese, in particolare della cultura femminile, e soprattutto nell'avvenire della lingua volgare» (p. LI). In effetti, è manifesta la volontà di usare la traduzione come pratica di arricchimento e sviluppo della lingua francese. La presente edizione non solo fornisce una pièce interessante per la storia dell'italianismo in Francia, ma serve anche allo storico della lingua francese, in quanto nell'introduzione Colette Winn fa un'accurata analisi (pp. XLVII-LXVII) delle caratteristiche linguistiche della traduzione di Marguerite de Cambis. In appendice troviamo un utile repertorio delle traduttrici francesi del Cinquecento e dell'inizio del Seicento. 